Kansas State University Libraries

New Prairie Press

\title{
CONFIDENCE INTERVALS FOR SOIL PROPERTIES BASED ON DIFFERING STATISTICAL ASSUMPTIONS
}

Fred J. Young

R. David Hammer

Jon M. Maatta

Follow this and additional works at: https://newprairiepress.org/agstatconference

Part of the Agriculture Commons, and the Applied Statistics Commons

\section{(c) (1) $\Theta(9$}

This work is licensed under a Creative Commons Attribution-Noncommercial-No Derivative Works 4.0 License.

\section{Recommended Citation}

Young, Fred J.; Hammer, R. David; and Maatta, Jon M. (1992). "CONFIDENCE INTERVALS FOR SOIL PROPERTIES BASED ON DIFFERING STATISTICAL ASSUMPTIONS," Conference on Applied Statistics in Agriculture. https://doi.org/10.4148/2475-7772.1397

This is brought to you for free and open access by the Conferences at New Prairie Press. It has been accepted for inclusion in Conference on Applied Statistics in Agriculture by an authorized administrator of New Prairie Press. For more information, please contact cads@k-state.edu. 


\section{CONFIDENCE INTERVALS FOR SOIL PROPERTIES BASED ON DIFFERING STATISTICAL ASSUMPTIONS}

Fred J. Young, R. David Hammer, and Jon M. Maatta

(USDA-Soil Conservation Service, University of MissouriColumbia, and Plymouth state College, respectively)

\section{ABSTRACT}

Agricultural soil management is becoming increasingly precise as technology advances and as environmental concerns increase. Soil surveys are a readily available source of soils information, but soil properties are reported as generalized values or generic ranges. A need exists to define the central tendencies of soil properties in a rigorous, quantified fashion. Statistically, the central tendency is best expressed as confidence intervals about means or medians. Transect sampling was used to collect data on soil properties within a soil survey map unit. Key questions for data analysis include assumptions of independence within transects and normality. The choice of statistical method is based on assumptions about the data and on the sampling scheme. Narrower confidence intervals resulted from assumptions of independence within transects and normal distributions of soil property values. Wider confidence intervals were obtained if assumptions of independence and normality were not made. For transect sampling in general, and these data in particular, the wider confidence intervals seem most appropriate.

Contribution from the Missouri Agricultural Experiment Station Journal Series Number 11,716. 


\section{INTRODUCTION}

All agricultural workers recognize that soils are variable, and that this variability can and does influence crop management and yield. However, the nature of this variability is often difficult to perceive. The primary reference document for soil variability is the local county soil survey, published by the USDA - Soil conservation service. The soil survey maps partition the county into a number of different map units, each of which presumably minimizes internal heterogeneity. In the Midwest, most map units are named as phases of soil series; for example, "Marshall silt loam, 5 to 9 percent slopes, eroded".

Most studies of variability within map units have focused on the extent of one or more soil series within the map unit (e.g. Powell and springer, 1965, wilding et al., 1965, steers and Hajek, 1979, Edmonds et al., 1982). Less has been done to accurately define either the central tendencies or variabilities of specific soil properties within these map units. De Gruijter and Marsman (1985) used point transects to sample various map units within a soil survey in the Netherlands. Confidence intervals were developed for means of soil properties based on formulas in Cochran (1977). Young et al. (1991) adapted these techniques to production soil surveys in the USA.

The objectives of this paper are: 1) apply a sampling scheme to a soil survey map unit in a fashion that is compatible with production soil survey methods, and 2) develop and compare confidence intervals for central tendencies based on various assumptions about normality and independence.

\section{MATERIALS AND METHODS}

Sampling strategy:

A single map unit within the soil survey of Boone County, Missouri was selected for study. This map unit, Eudora silt loam, occurs on the flood plain of the Missouri River, on relatively high positions.

Randomly selected point transects were used to sample the map unit. Transects have been widely used in soil survey work (e.g. Steers \& Hajek, 1979; Bigler \& Liudahl, 1984; De Gruijter \& Marsman, 1985), and are required for 
documentation purposes in Missouri soil surveys. Transects were used instead of individual points, because of the difficulties involved in physically locating individual, randomly selected points on the landscape. Random selection of individual sampling points is generally not used in soil survey work.

To establish a frame from which to sample, potential transects were subjectively defined and located within delineations of the map unit. Although more objective methods have been used to locate transects (e.g. De Gruijter \& Marsman, 1985), subjective placement of potential transects is the norm in production soil surveys (e.g. Steers \& Hajek, 1979; Young et al., 1991). These potential transects were distributed as evenly as possible throughout all delineations, and were placed to avoid edge effects. Each potential transect represents roughly 40 acres, so 82 potential transects were located throughout the 3260 acres of this map unit. Some potential transects were subdivided to insure that delineations smaller than 40 acres could be included in the sampling population.

The sampled population thus consisted of 82 potential transects, whereas the target population consisted of the essentially infinite number of individual soils within the map unit. The representation of the target population by this sampled population is not exact, and is undoubtedly biased to some unknown degree. Specifically, edge effects and anomalies such as roads were deliberately excluded from the sampled population. This is justified based on the perceptions and expectations of soil survey users. Most people do not consider roads, buildings, quarries, etc. to be part of the target population of soils, and do not wish information about them. Boundaries between soil types are generally difficult to locate exactly in the field; transition zones are common. Farmers and other informed users of soil surveys recognize that soils may change gradually, and accept the idea that soil survey information may not be accurate near boundaries. Therefore, although the sampled population may not accurately reflect the target population in some ways, we contend that it adequately represents the target population for the intended users of the information. 
The flood plain was stratified into three areas prior to potential transect placement. The stratification was based on natural geographic separations, and was used to determine if significant differences existed between strata.

From the 82 potential transects, 12 were randomly selected for sampling. Random selection was conducted separately on each stratum. The number of transects selected in each of the three areas was roughly proportional to the extent of the map unit in that area. All transects were roughly Iinear, with ten observations spaced at 200 foot intervals. soil observations and samples were taken at each point along the transects. Observations included horizon thicknesses and depth to wetness-induced mottling. Laboratory analyses of samples provided data on particle size distributions, $\mathrm{pH}$ and organic carbon.

Samples were taken from the surface layer ("A" horizon), the horizon immediately below the surface layer ("C1" horizon), and the material between 100 and $142 \mathrm{~cm} \mathrm{("C3"} \mathrm{horizon).} \mathrm{The}$ $100 \mathrm{~cm}$ sampling break is not based on naturally occurring soil horizons, but is used to facilitate soil taxonomic issues not discussed here. Some soils had a strongly contrasting textural change above $100 \mathrm{~cm}$, e.g. the texture changed from a silt loam in the C1 horizon to a sand at 75 $\mathrm{cm}$. Such materials were sampled as "C2" horizons.

Twelve interval level properties are reported in this paper. They are organic carbon content, thickness, and $\mathrm{pH}$ of the surface horizon (the "A" horizon), and clay, total sand, and sands coarser than very fine sand for each of the $A, C 1$ and C3 horizons. The C2 horizon data are not available for all of the soils and are not reported. The distinction between total sand and sand coarser than very fine sand is important for soil taxonomic reasons, primarily due to engineering criteria.

Statistical Analyses:

Both classical and nonparametric methods were used to determine confidence intervals. Classical methods were used to find the confidence interval for the mean, as follows: $\sigma_{h}^{2}=\varepsilon\left(y_{i}-\mu_{h}\right)^{2} / n_{h}-1 \quad$ (note: $\varepsilon$ is summation symbol) where $\sigma_{h}^{2}=$ variance of stratum $h$, $\mu_{\mathrm{h}}=$ mean value for the sampled property in stratum $\mathrm{h}$, 
$Y_{i}=$ value for sample $i$, and

$n_{h}=$ number of samples in stratum $h$.

Because stratification was used, equation 1 was applied to the samples taken from each stratum separately. A weighted mean and variance were then calculated as follows:

$\mu_{\mathrm{st}}=\varepsilon\left[\left(\mathrm{N}_{\mathrm{h}} / \mathrm{N}\right) * \mu_{\mathrm{h}}\right]$

where $\mu_{\mathrm{st}}=$ the overall weighted mean,

$N_{h}=$ the sample population in stratum $h$, and

$\mathrm{N}=$ the overall sample population.

$\sigma_{\text {st }}^{2}=\varepsilon\left[\left(\mathrm{N}_{\mathrm{h}}{ }^{2} / \mathrm{N}^{2}\right) *\left(\sigma_{\mathrm{h}}{ }^{2} / \mathrm{n}_{\mathrm{h}}\right)\right]$

where $\sigma_{\text {st }}^{2}=$ the overall weighted variance,

$n_{h}=$ the sample size in stratum $h$.

The normal confidence interval is:

$\mu_{\text {st }}+\varepsilon_{c}-t * \sigma_{\text {at }} / \mathrm{n} \cdot 5$

where $t=$ student's $t$ with $n-1$ degrees of freedom at the desired confidence level.

Confidence intervals can be determined for individual sample points or for transect means. If individual sample points are considered, then $y_{i}=$ value for an individual point sample $i$, and $n=$ number of sample points, which in this case is 120. If transect means are considered, then $y_{i}=$ mean value for transect $i$, and $n=$ number of transects, which in this case is 12 .

The first method analyses the data as if they were taken from a single-stage, simple random sample (or stratified random sample, in this case). This is a common method of analysis of transect data in soil surveys. The second method recognizes that this is a two-stage sampling plan, with the first stage as a simple random sample of transects. The second stage could be considered as a cluster sample of the 10 observations along the transect, or perhaps more appropriately, as a systematic sample of 10 soils from the many possible soils along the transect.

The nonparametric sign test and the wilcoxon signed-ranks test were used to build confidence intervals for the median (calculations are based on methods presented by Daniel, 1990). Confidence intervals can be built based on individual sample point values as well as on transect means. 
The confidence interval for sign test transect means is at a 96\% confidence level, due to the nature of the binomial tables for $n=12$ at 0.50 probability. The confidence interval for the wilcoxon signed-rank test transect means is at a 94.8\% confidence level for similar reasons. Largesample approximations have been used to determine the critical values for individual points at 95\% confidence levels. Wilcoxon signed-ranks values were calculated with a program written in QuickBasic.

The Kolmogorov-Smirnov test and the Lilliefors test (which utilizes the K-S test statistic) were used with SYSTAT (Wilkinson, 1990) software to test the hypothesis that each of the soil properties is normally distributed. Small $P$ values indicate that normality is unlikely. Daniel (1990) indicates that when the population parameters are estimated from the sample data, as is the case here, Lilliefors is the most appropriate test.

Values for skewness and kurtosis were calculated for each soil property using SYSTAT (Wilkinson, 1990) software, version 5.01. Snedecor and Cochran (1980) tabulate critical values for skewness and kurtosis at the 95\% and 99\% levels of significance (one-tailed). For a sample size of 125 , the 99\% value for skewness is 0.508 . There is a 99\% probability that a population with a skewness value of greater than 0.508 will be skewed to the right.

\section{RESULTS AND DISCUSSION}

The choice of methods for analyzing these data depends on the assumptions concerning the sampling scheme, sample population distribution and sample independence. If the sample data are from a single-stage, simple (or stratified) random sample, and consist of normally distributed, independent observations, then confidence intervals for the mean can be built using a sample size of 120. Sample distribution and independence are examined below. 
Distribution:

The first step in data analysis was to examine the frequency distributions of the data for each property. "A" horizon clay (Fig. 1a), sand (Fig. 1b), thickness (Fig. 1C), and pH (Fig. 1d) are examples of these distributions. Note that none of the distributions appear normal. All of the distributions appear skewed to various degrees, especially $\mathrm{pH}$, which is skewed left, and sands coarser than very fine sand, which is skewed right. Clay appears bimodal and slightly skewed.

Departures from normality were statistically evaluated with the Kolmogorov-Smirnov and Lilliefors tests. The assumption of normality is rejected for all twelve soil properties with the Kolmogorov-Smirnov test (ali $P$ values are 0.000). The Lilliefors test, however, indicates that the assumption of normality cannot be rejected for the distribution of organic carbon values $(P=0.172)$.

Assumptions of normality may not be warranted for most of these sample population distributions. Properties that are strongly skewed, such as $\mathrm{pH}$ and the coarser sand fraction, are best analyzed either by transforming the data to achieve normality, or by using distribution-free methods.

Independence:

Transects were the "individuals" randomly selected for sampling. Transects, therefore, are independent. However, the independence of observations within transects is questionable. Some degree of spatial dependence probably exists between observations within transects. The intraclass correlation coefficient (Cochran, 1977) is an indicator of this dependence, and can be used to estimate the increase in variance caused by using cluster or systematic sampling as opposed to simple random sampling. other workers have examined spatial dependence directly by calculating autocorrelations (Lanyon \& Hall, 1981) or semivariances (Campbell, 1978). The degree of spatial dependence within these transects is not known.

A sample size of 120 violates the assumption of independence to some degree, depending on the spatial variability structure of the measured soil property. Greater spatial dependence reduces variability, resulting in narrow 
confidence intervals that overstate the degree of confidence.

Transect means can be used as sample individuals to fully satisfy the assumption of independence. In this case the sample size is 12. One might expect the distribution of these transect means to approach normality, in accordance with the Central Limit Theorem. However, superposition of the transect means frequency distribution on the frequency distribution of point observations indicates that these means reflect the skewed distributions of the point observations. This suggests that observations within transects are dependent, and are providing redundant information to some degree.

Stratification further damages assumptions of normality. Sample sizes within each stratum are small, so large sample Central Limit Theorem assumptions cannot be applied.

Confidence Intervals:

Confidence intervals for the central tendencies of these soil properties can be calculated in a number of ways, depending on the assumptions made regarding the distribution and independence. If normality and independence between point observations are assumed, classical methods can be used with $n=120$. If normality is assumed but transects rather than points are considered independent, then classical methods can be used with $n=12$.

If normality is rejected, then distribution-free methods are used. The wilcoxon signed-ranks test is used for symmetric populations, and the sign test is used for skewed

populations. The sample size is either the number of point observations (120) or the number of transects (12), depending on the assumption of independence between points.

Table 1 compares confidence intervals for means based on the utilization of point observations versus using transect means, and assuming normality. For every soil property, the use of transect means reduced the standard deviation but widened the confidence interval. The higher number of observations of individual pedons versus transects reduces the standard error of the mean, and narrows the confidence interval. Use of transect means reduces the measured 
variability of a soil property with a loss of confidence in the accuracy of the sample mean.

Table 2 compares confidence intervals for medians for point observations versus transect means, without the assumption of normality. The sign test is the method of choice, because most of the distributions are skewed. Again, transect means produced wider intervals because of the sample size difference. These differences were, in general, slightly less and were more variable than those utilizing parametric procedures.

Table 3 compares the confidence intervals for means with the confidence intervals for medians, utilizing the transect means as the sample individuals. "Difference" is computed as mean width minus median width. Negative numbers indicate that the confidence interval for the mean is narrower than that for the median.

Seven of the 12 soil properties have wider median confidence intervals than mean confidence intervals, while 3 are narrower and 2 are of identical width. Of the 7 wider median intervals, 3 are only slightly so. Confidence in the mean is not consistently better than confidence in the median.

Although median intervals are generally not symmetric with the mean intervals, neither are they greatly offset. The largest differences occur in highly variable soil properties, but these intervals are so wide as to have Iimited usefulness.

Transformations:

Another approach is to attempt to normalize the data by mathematical transformation, then use parametric techniques to develop confidence intervals from the transformed data. The confidence intervals are then back-transformed for use.

Table 4 presents an evaluation of the most effective transformations of the 7 most highly skewed properties. only 4 of the 7 properties were effectively normalized at a probability level of 0.05 , using Lililefors test.

Transformation is not effective for all properties. However, skewness was decreased for all properties after transformation. 
Table 5 compares confidence intervals from the original data versus transformed data. Calculations are for individual sample points $(n=120)$. The confidence intervals for the transformed data have been back-transformed for ease of interpretation and comparison.

No consistent differences in width occur between the transformed and original data. Some transformed intervals are wider than the original, some are narrower and some are the same. All of the transformed intervals are offset from the original in ways which counteract the skewness of the original data. However, some appear to overcompensate. The "fsplus" intervals of the transformed data don't even overlap the intervals based on the original data.

Confidence intervals based on transformed data probably provide a better measure of central tendency for these skewed properties than do intervals based on the original data. However, these intervals may be difficult to explain and interpret to users of soils information. For example, the confidence interval for A horizon thickness is really the antilog of the confidence interval for the log of the mean A horizon thickness. Difficulty in interpretability and variable success in transforming the data limit the usefulness of mathematical transformations of soil survey data.

\section{SUMMARY AND CONCLUSIONS}

Transect sampling is an efficient and widely accepted method of data collection in soil survey. It is most appropriately considered as a two-stage sampling scheme, with random selection in the first stage and systematic sampling in the second stage. If data are analyzed as if simple random sampling were conducted, then assumptions of independence may be violated. Assumptions of independence and application of simple random sampling analysis will result in much narrower confidence intervals for either means or medians, but true confidence levels may not be so high as assumed by the calculations.

Stratification of the map unit may be useful if trends are suspected within the map unit. However, stratification increases computational complexity, decreases the power of 
the analysis, and further erodes already tenuous assumptions of normality.

Assumptions of normality are suspect for most soil properties in this map unit, whether considering individual point observations or means of transects. Many of the properties are skewed. Confidence intervals for medians based on nonparametric procedures may provide more realistic estimates of central tendencies. These confidence intervals will be slightly different than intervals for means, but are not necessarily wider.

Transformations may be helpful in normalizing data for some soil properties. However, different soil properties require different transformations. Intervals calculated with parametric methods based on transformed data may provide better estimates of central tendency than intervals based on the original data. However, soil survey users may find these back-transformed intervals to be confusing.

Different soil properties have different variabilities and distributions. This map unit is in recent calcareous alluvial sediments, with high particle size variability but relatively low variability in other properties such as pH and organic carbon. Central tendencies of some properties were adequately estimated with the density of sampling employed, whereas others were not. Soils on other parent materials, or even on other parts of the flood plain, will have different patterns of variability.

The need for more precisely quantified information on soil properties within soil survey map units will increase in the future. Rising energy and agricultural chemical costs coupled with increasing concerns about water quality will drive the trend towards ever more precise soil management. There is increasing interest within the soil survey community in objective, quantified procedures, but there is also a divergence of opinion about how to do so. Most field soil mappers are not knowledgeable about statistical technique and theory, and most statisticians are not familiar with soil systems. A need exists for statisticians and soil scientists to work together to sample, analyze and describe soil systems in appropriate ways that will serve the needs of the agricultural community. 


\section{REFERENCES}

Bigler, R.J., and K.J. Liudahl. 1984. Estimating map unit composition. Soil Survey Horizons 25:21-25.

Campbell, J.B. 1978. Spatial variation of sand content and pH within single contiguous delineations of two soil mapping units. Soil Sci. Soc. Am. J. 42:460-464.

Cochran, W.G. 1977. Sampling techniques. third edition. John Wiley \& Sons, New York.

Daniel, W.W. 1990. Applied nonparametric statistics. second edition. PWS-Kent, Boston, Massachusetts.

de Gruijter, J.J., and B.A. Marsman. 1985. Transect sampling for reliable information on mapping units. p. 150-163. In D.R. Nielsen and J. Bouma (ed.) Soil spatial variability. Proc. workshop ISSS and SSSA, Las Vegas, NV. 30 Nov.-1 Dec. 1984. PUDOC, Waginengan, Netherlands.

Edmonds, W.J., S.S. Iyengar, L.W. Zelazny, M. Lentner, and C.D. Peacock. 1982. Variability in family differentia of soils in a second-order soil survey mapping unit. Soil Sci. Soc. Am. J. 46:88-93.

Lanyon, L.E., and G.F. Hall. 1981. Application of autocorrelation analysis to transect data from a drainage basin in eastern ohio. Soil Sci. Soc. Am. J. 45:368-373.

Powell, J.C., and M.E. Springer. 1965. Composition and precision of classification of several mapping units of the Appling, Cecil, and Lloyd series in Walton County, Georgia. Soil Sci. Soc. Am. Proc. 29:454-458.

Snedecor, G.W., and W.G. Cochran. 1980. Statistical methods. 7th ed. Iowa State Univ. Press, Ames, IA

Steers, C.A., and B.F. Hajek. 1979. Determination of map unit composition by a random selection of transects. Soil Sci. Soc. Am. J. $43: 156-160$.

Wilding, L.P., R.B. Jones, and G.M. Schafer. 1965. Variation of soil morphological properties within Miami, Celina, and Crosby mapping units in west-central Ohio. Soil Sci. Soc. Am. Proc. 29:711-717.

Wilkinson, L. 1990. SYSTAT: the system for statistics. SYSTAT, Inc., Evanston, Illinois.

Young, F.J., J.M. Maatta, and R.D. Hammer. 1991. Confidence intervals for soil properties within map units. In M.J. Mausbach and L.P. Wilding, ed., Spatial variabilities of soils and landforms. Soil Sci. Soc. Am. Spec. Pub. 28, Soil Sci. Soc. Am., Madison, Wi. 

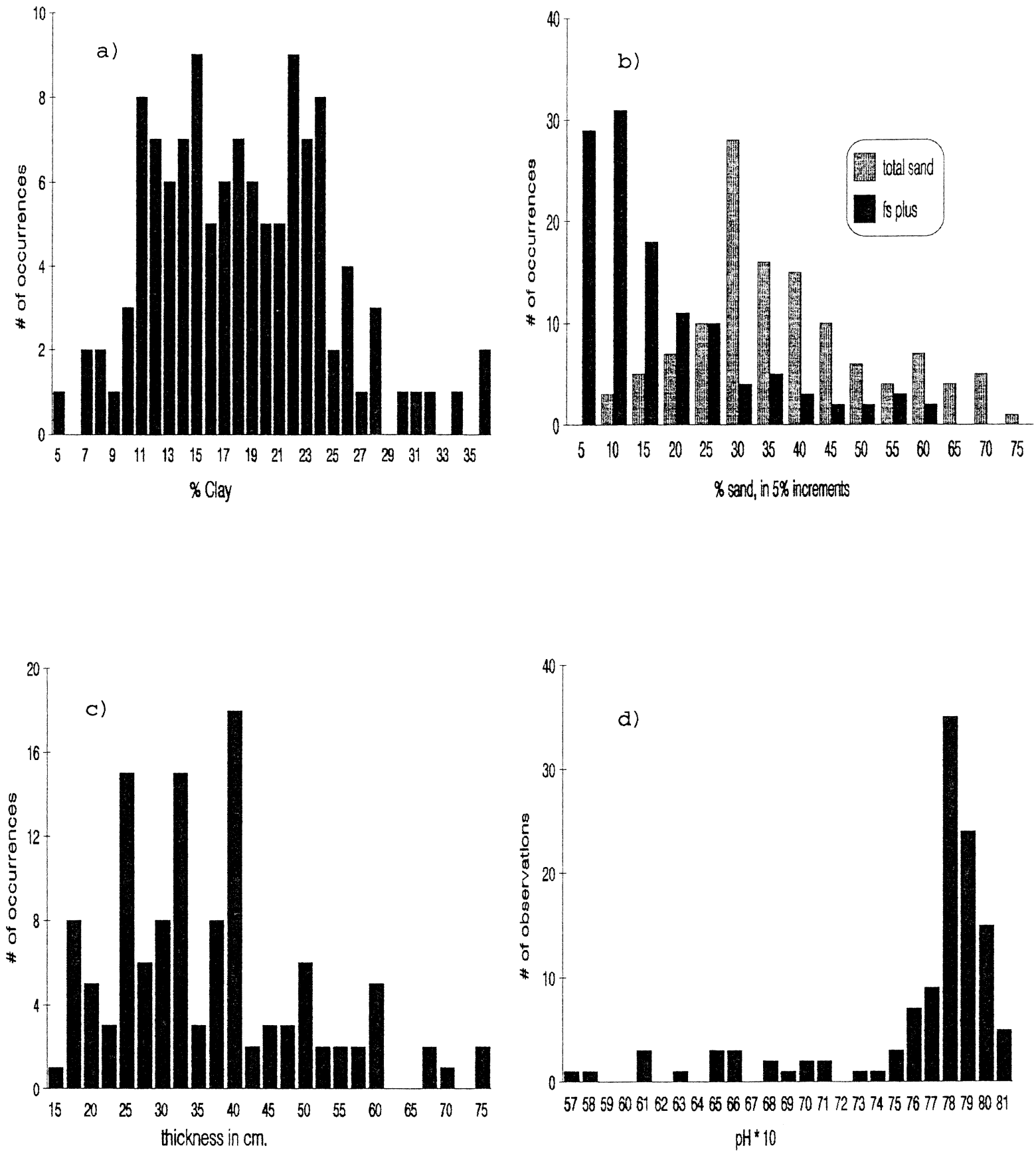

Figure 1: Frequency distributions of 4 soil properties for 120 samples. a) A horizon clay content b) A horizon sand content ("fs plus" is the fraction of sand that is fine sand and coarser) c) A horizon thickness, d) A horizon $\mathrm{pH}$ 
Table 1: Comparison of statistical methods, using transect means versus using individual points.

\section{A Horizon Properties}

Thickness $\mathrm{pH}$ Organic Carbon

\begin{tabular}{||l|c|c|c|c|c|c||}
\hline & $\begin{array}{c}\text { trans. } \\
\text { mean }\end{array}$ & point & $\begin{array}{c}\text { trans. } \\
\text { mean }\end{array}$ & point & $\begin{array}{c}\text { trans. } \\
\text { mean }\end{array}$ & point \\
\hline std dev & 11.85 & 13.62 & .46 & .53 & .20 & .25 \\
\hline $95 \%$ CI & $29-44$ & $34-39$ & $7.3-7.9$ & $7.5-7.7$ & $.8-1.0$ & $.86-.95$ \\
\hline CI width & 15 & 5 & 0.6 & 0.2 & 0.2 & 0.09 \\
\hline
\end{tabular}

응 Clay $\frac{\circ}{0}$ sand

FS PIUS

\begin{tabular}{||l|c|c|c|c|c|c|}
\hline & $\begin{array}{c}\text { trans. } \\
\text { mean }\end{array}$ & point & $\begin{array}{c}\text { trans. } \\
\text { mean }\end{array}$ & point & $\begin{array}{c}\text { trans. } \\
\text { mean }\end{array}$ & point \\
\hline std dev & 4.45 & 6.27 & 10.68 & 14.69 & 9.78 & 13.56 \\
\hline $95 \%$ CI & $15-21$ & $17-19$ & $29-43$ & $33-39$ & $9-21$ & $13-18$ \\
\hline CI width & 6 & 2 & 14 & 6 & 12 & 5 \\
\hline
\end{tabular}

C1 Horizon Properties

Clay o sand

FS PIUS

\begin{tabular}{||l|c|c|c|c|c|c||}
\hline & $\begin{array}{c}\text { trans. } \\
\text { mean }\end{array}$ & point & $\begin{array}{c}\text { trans. } \\
\text { mean }\end{array}$ & point & $\begin{array}{c}\text { trans. } \\
\text { mean }\end{array}$ & point \\
\hline std dev & 6.52 & 8.62 & 14.20 & 21.70 & 16.01 & 20.47 \\
\hline $95 \%$ CI & $10-19$ & $13-16$ & $34-52$ & $39-47$ & $7-28$ & $14-21$ \\
\hline CI width & 9 & 3 & 18 & 8 & 21 & 7 \\
\hline
\end{tabular}

C3 Horizon Properties

\% Clay $\quad$ sand

\begin{tabular}{|l|c|c|c|c|c|c||}
\hline & $\begin{array}{c}\text { trans. } \\
\text { mean }\end{array}$ & point & $\begin{array}{c}\text { trans. } \\
\text { mean }\end{array}$ & point & $\begin{array}{c}\text { trans. } \\
\text { mean }\end{array}$ & point \\
\hline std dev & 7.23 & 10.03 & 22.06 & 31.71 & 19.21 & 29.11 \\
\hline $95 \%$ CI & $9-18$ & $13-16$ & $31-59$ & $39-50$ & $8-32$ & $15-25$ \\
\hline CI width & 9 & 3 & 28 & 11 & 24 & 10 \\
\hline
\end{tabular}


Table 2: Confidence intervals for the medians of twelve soil properties, using the sign test. Rows marked "points" use point values as sample individuals, with $\mathrm{n}=120$, and $\mathrm{CI}$ at 95\%. Rows marked "transect" use transect means as sample individuals, with $\mathrm{n}=12$ and $\mathrm{CI}$ at $96 \%$.

A Horizon Properties

\begin{tabular}{|l|c|c|c|c|c|c||}
\hline & thick. & \& Clay & 8 Sand & fs plus & pH & Org. C \\
\hline $\begin{array}{l}\text { CI, } \\
\text { points }\end{array}$ & $33-38$ & $16-19$ & $29-36$ & $8-13$ & $\begin{array}{c}7.77- \\
7.83\end{array}$ & $.83-.93$ \\
\hline $\begin{array}{l}\text { CI, } \\
\text { transect }\end{array}$ & $26-46$ & $14-21$ & $27-42$ & $7-19$ & $7.2-7.9$ & $.8-1.0$ \\
\hline $\begin{array}{l}\text { width, } \\
\text { points }\end{array}$ & 5 & 3 & 7 & 5 & 0.06 & 0.1 \\
\hline $\begin{array}{l}\text { width, } \\
\text { transect }\end{array}$ & 20 & 7 & 15 & 12 & 0.7 & 0.2 \\
\hline
\end{tabular}

C1 Horizon Properties

\begin{tabular}{|l|c|c|c|}
\hline & \& Clay & \& Sand & Fs plus \\
\hline $\begin{array}{l}\text { CI, } \\
\text { points }\end{array}$ & $11-14$ & $33-48$ & $8-13$ \\
\hline $\begin{array}{l}\text { CI, } \\
\text { transect }\end{array}$ & $11-16$ & $36-47$ & $8-20$ \\
\hline $\begin{array}{l}\text { width, } \\
\text { points }\end{array}$ & 3 & 15 & 5 \\
\hline $\begin{array}{l}\text { width, } \\
\text { transect }\end{array}$ & 5 & 11 & 12 \\
\hline
\end{tabular}

C3 Horizon Properties

\begin{tabular}{||l|c|c|c||}
\hline & \& Clay & \% Sand & Fs plus \\
\hline $\begin{array}{l}\text { CI, } \\
\text { points }\end{array}$ & $9-14$ & $31-50$ & $3-14$ \\
\hline $\begin{array}{l}\text { CI, } \\
\text { transect }\end{array}$ & $6-20$ & $27-66$ & $4-37$ \\
\hline $\begin{array}{l}\text { width, } \\
\text { points }\end{array}$ & 5 & 19 & 11 \\
\hline $\begin{array}{l}\text { width, } \\
\text { transect }\end{array}$ & 12 & 39 & 33 \\
\hline
\end{tabular}


Table 3: Comparison of confidence intervals for the mean and confidence intervals for the median, both based on transect means as sample individuals.

A Horizon Properties

\begin{tabular}{|l|c|c|c|c|c|c|}
\hline & thick. & \& Clay & \& Sand & fs plus & pH & Org. C \\
\hline $\begin{array}{l}\text { CI, } \\
\text { median }\end{array}$ & $26-46$ & $14-21$ & $27-42$ & $7-19$ & $7.2-7.9$ & $.8-1.0$ \\
\hline $\begin{array}{l}\text { CI, } \\
\text { mean }\end{array}$ & $29-44$ & $15-21$ & $29-43$ & $9-21$ & $7.3-7.9$ & $.8-1.0$ \\
\hline Difference & -5 & 0 & -1 & 0 & -0.1 & -0.1 \\
\hline
\end{tabular}

C1 Horizon Properties

\begin{tabular}{|l|c|c|c||}
\hline & \& Clay & \& Sand & Fs plus \\
\hline $\begin{array}{l}\text { CI, } \\
\text { median }\end{array}$ & $11-16$ & $36-47$ & $8-20$ \\
\hline $\begin{array}{l}\text { CI, } \\
\text { mean }\end{array}$ & $10-19$ & $34-52$ & $7-28$ \\
\hline Difference & 4 & 7 & 9 \\
\hline
\end{tabular}

C3 Horizon Properties

\begin{tabular}{|l|c|c|c|}
\hline & \& Clay & \& Sand & Fs plus \\
\hline $\begin{array}{l}\text { CI, } \\
\text { median }\end{array}$ & $6-20$ & $27-66$ & $4-37$ \\
\hline $\begin{array}{l}\text { CI, } \\
\text { mean }\end{array}$ & $9-18$ & $31-59$ & $8-32$ \\
\hline Difference & -5 & -11 & -9 \\
\hline
\end{tabular}


Table 4: Transformations used on the 7 most highly skewed soil properties. Lilliefors $P$ is the probability that the distribution approximates normality.

\begin{tabular}{||l|l|l||}
\hline Property & transformation & Lilliefors P \\
\hline A thick. & log & .06 \\
\hline pH & antilog & .003 \\
\hline A fsplus & log & .806 \\
\hline C1 clay & sq. root & .001 \\
\hline C3 clay & sq. root & .118 \\
\hline C1 fsplus & log & .374 \\
\hline C3 fsplus & log & .003 \\
\hline
\end{tabular}

Table 5: Comparison of confidence intervals using the original data versus using transformed data.

\begin{tabular}{|l|l|l||}
\hline Property & original & transformed \\
\hline A thick. & $34-39$ & $32-37$ \\
\hline pH & $7.5-7.7$ & $7.4-8.2$ \\
\hline A fsplus & $13-18$ & $9-12$ \\
\hline C1 clay & $13-16$ & $12-15$ \\
\hline C3 clay & $13-16$ & $10-14$ \\
\hline C1 fsplus & $14-21$ & $7-11$ \\
\hline C3 fsplus & $15-25$ & $5-10$ \\
\hline
\end{tabular}

